\title{
Pharyngitis, CTCAE
}

National Cancer Institute

\section{Source}

National Cancer Institute. Pharyngitis, CT CAE. NCI Thesaurus. Code C143758.

A disorder characterized by inflammation of the throat. 